\title{
Optimizing battery sizes of plug-in hybrid and extended range electric vehicles for different user types
}

\author{
Martin Redelbach, Enver Doruk Özdemir*, Horst E. Friedrich \\ Institute of Vehicle Concepts, German Aerospace Center (DLR), Stuttgart, Germany
}

\section{H I G H L I G H T S}

- Optimization of the battery size of PHEVs and EREVs under German market conditions.

- Focus on heterogeneity across drivers (e.g. mileage, trip distribution, speed).

- Optimal battery size strongly depends on the driving profile and energy prices.

- OEMs require a modular design for their batteries to meet individual requirements.

\section{A R T I C L E I N F O}

\section{Article history:}

Received 11 February 2014

Received in revised form

4 April 2014

Accepted 28 May 2014

Available online 19 June 2014

Keywords:

Electric driving range

Driving profiles

Total cost of ownership (TCO)

\begin{abstract}
A B S T R A C T
There are ambitious greenhouse gas emission (GHG) targets for the manufacturers of light duty vehicles. To reduce the GHG emissions, plug-in hybrid electric vehicle (PHEV) and extended range electric vehicle (EREV) are promising powertrain technologies. However, the battery is still a very critical component due to the high production cost and heavy weight. This paper introduces a holistic approach for the optimization of the battery size of PHEVs and EREVs under German market conditions. The assessment focuses on the heterogeneity across drivers, by analyzing the impact of different driving profiles on the optimal battery setup from total cost of ownership (TCO) perspective.

The results show that the battery size has a significant effect on the TCO. For an average German driver (15,000 km/a), battery capacities of $4 \mathrm{kWh}$ (PHEV) and $6 \mathrm{kWh}$ (EREV) would be cost optimal by 2020. However, these values vary strongly with the driving profile of the user. Moreover, the optimal battery size is also affected by external factors, e.g. electricity and fuel prices or battery production cost. Therefore, car manufacturers should develop a modular design for their batteries, which allows adapting the storage capacity to meet the individual customer requirements instead of "one size fits all".
\end{abstract}

(c) 2014 Elsevier Ltd. All rights reserved.

\section{Introduction}

The reduction of greenhouse gas emissions (GHG) and petroleum consumption is the major challenge for the transport sector in the 21th century. Transport is responsible for about $20 \%$ of total GHG emissions in the EU in 2011 (EEA, 2013). The European Commission aims to cut $60 \%$ of $\mathrm{CO}_{2}$ emissions by 2050 with regard to the 1990 level (European Commission, 2011). In this context, the manufacturers of light duty vehicles, which are responsible for $75 \%$ of total transport GHG emissions (EC, 2012), are required to decrease average $\mathrm{CO}_{2}$ emissions of new passenger cars to $95 \mathrm{~g} / \mathrm{km}$ by 2020 . However, the new regulation includes a phase-in period, which allows OEMs to meet this target with only $95 \%$ of their car

\footnotetext{
* Corresponding author.

E-mail address: Doruk.Oezdemir@dlr.de (E.D. Özdemir).
}

fleet in 2020. Starting in 2021, $100 \%$ of the relevant fleet has to fulfill $95 \mathrm{~g} / \mathrm{km}$ limit. Even more ambitious regulations $(68-78 \mathrm{~g} / \mathrm{km})$ are currently discussed for the following period 2020-2025 (European Parliament, 2013). Achieving these targets will not be feasible with conventional internal combustion engines. One of the most promising powertrain technologies are plug-in hybrid electric vehicle (PHEV) and extended range electric vehicles (EREV) (Shiau et al., 2009, Peterson et al., 2011, Özdemir and Hartmann, 2012, Bandivadekar et al., 2008). They combine local emission free driving of battery electric vehicles with the unrestricted driving range of conventional cars powered by gasoline or diesel (Peterson, Michalek, 2013). However, the battery is still a very critical component due to the high production cost and heavy weight (Shiau et al., 2009, Özdemir and Hartmann, 2012, Bandivadekar et al., 2008, Peterson, Michalek, 2013, Shiau et al., 2010, Shiau, 2011). Therefore, the right sizing of the battery is the key for electric powertrains to meet customer expectations and become cost competitive against 
conventional technologies. There are several recent studies that focus on the optimal battery size for grid connected hybrid electric vehicle for the US market (Shiau et al., 2009, Peterson, Michalek, 2013, Shiau et al., 2010, Shiau, 2011, Wu et al., 2011), and for the European market (Özdemir and Hartmann, 2012, Ernst et al., 2011, Plötz et al., 2012).

Among the US studies, Shiau et al. (2009, 2010) compared several PHEVs with different electric driving ranges with regard to the economic and environmental feasibility for an average US driver. In their analyses, best suitable battery size is determined for different targets such as minimum net life cycle cost, and minimum GHG emissions. The results show that the optimum battery size is significantly lower for minimum cost target than for minimum GHG emissions target for a specific driver type. Furthermore, Shiau and Michalek (2011) analyzed the effect of different average daily driven distances. The results show that a switch from conventional vehicle to a PHEV reduces the life cycle GHG emissions significantly. Economic implications are not covered in this work. Peterson and Michalek, (2013) investigated the net life cycle air emissions from PHEVs for different battery sizes and charging strategies for an average US driver. The results show that emissions of $\mathrm{CO}_{2}, \mathrm{SO}_{2}$ and $\mathrm{NO} x$ can be reduced with increasing battery size. Wu et al. (2011) analyzed the component sizing of plug-in vehicles with the aim to optimize the powertrain costs under different cycles. However, in this study only the production costs of the powertrain are considered. The optimization did not include running costs (such as gasoline or electricity from the grid), which does not represent total cost of ownership (TCO).

Besides the studies for the US market, there are also studies that concentrated on the European (especially German) market. Özdemir and Hartmann (2012) analyzed the energy consumption of PHEVs (for grid electricity and fuel), costs and GHG abatement costs depending on the electric driving range for an average driver under the assumed German market conditions in 2030. The results show that the optimum electric driving range for minimum costs and for minimum GHG abatement costs are between $12-32 \mathrm{~km}$, and between $16-23 \mathrm{~km}$, respectively. Furthermore, they also investigated the effect of changing oil price, annual mileage, battery costs, energy consumption and interest rate. Main factors that influence the results are identified as annual mileage and oil price. Ernst et al. (2011) investigated similarly the economic implications and $\mathrm{CO}_{2}$ emissions of PHEVs with different battery sizes for an average German driver under the assumed market conditions in 2020. The results show that PHEVs are cost competitive, if the battery size is small (e.g. $4 \mathrm{kWh}$ ). Furthermore, the recharging strategies are not found to be significant for the cost calculation results. Plötz et al. (2012) focused on the analytical solution of the TCO minimization problem for PHEV drivers with respect to the battery size. The results show that the optimal battery size is about $10 \mathrm{kWh}$ (50 km electric driving range) for battery costs of $200 \mathrm{EUR} / \mathrm{kWh}$ for the average German driver.

Although the impact of PHEV battery size on costs and GHG emissions has already been studied in the literature in some detail, existing studies neglect some significant aspects in this context. Firstly, they do not account for the heterogeneity which can be observed across different driver types. The papers discussed before typically assume a constant driving distance (Shiau et al., 2009) or a trip distribution based on an average driver (Özdemir and Hartmann, 2012, Plötz et al., 2012, Ernst et al., 2011). However, in reality, the daily driving distance varies significantly during one year and across different user types (DLR \&amp; Infas, 2010). Secondly, previous studies do not consider that drivers with higher annual mileage typically spend more time on motorways with a higher average velocity than that by drivers with lower annual mileage, which in consequence effects the energy consumption and the share of electric driving of the PHEV. In this context,
Ernst et al. (2011) identifies different driving profiles for PHEVs as a future research area. Thirdly, none of the existing studies considered the technical differentiation between hybrid architectures such as parallel (PHEV, plug-in hybrid electric vehicle) and serial (EREV, extended range electric vehicle) powertrain configurations. Lastly, batteries are subject to degradation and aging processes which require a substantial oversizing of the initial energy capacity, which is not taken into account by some studies (e.g. Plötz et al., 2012).

Therefore, this paper aims to close these gaps by introducing a holistic approach for the optimization of the battery size of PHEVs and EREVs under German market conditions by considering the battery degradation and secondary effects of additional mass on the energy consumption. The assessment puts special focus on the heterogeneity across drivers, by analyzing the impact of different driving profiles on the optimal battery setup from total cost of ownership perspective for the year 2020 in Germany. Furthermore, specific $\mathrm{CO}_{2}$ emissions (tank to wheel - TTW and well to wheel - WTW) for grid connected cars are analyzed as a function of battery size. The most relevant data for this analysis, e.g. energy consumption or battery costs, is based on own vehicle simulations and detailed cost models.

In the following, Section 2 introduces the methodology to identify a cost optimal design for the battery capacity of grid connected vehicles. Section 3 describes the underlying total cost of ownership model and the empirical data used to characterize the driving behavior. The model is applied to the situation of different driver types and the resulting implications on energy consumption, mobility cost and GHG emissions are discussed (Section 4). The sensitivity of the results with regard to changes in the underlying input parameters is analyzed to understand the dependences from external factors, e.g. energy prices. Finally, Section 5 summarizes the policy implications and gives an outlook on future research questions.

\section{Methodology}

The sizing of the battery has multiple implications on the technical properties and the financials of hybrid electric cars (see Fig. 1). The installed battery capacity directly affects the curb weight and the energy consumption of the car, which in combination determine the all-electric driving range. Besides the technical configuration of the powertrain, the share of electric driving is also influenced by the driving behavior of the user. In general, a larger battery capacity leads to a higher share of electric driving because more trips can be covered within the electric driving range of the car. As electric motors offer significantly better energy efficiency than internal combustion engines (ICE) a higher share of electric driving causes lower operating costs for the car holder and lower $\mathrm{CO}_{2}$ emissions. On the other hand, the production cost of the battery and the associated purchase price for the custumer increase with rising energy storage capacity. Consequently, the optimal battery size from the perspective of a car buyer is a tradeoff between one time investment costs and running costs over lifetime. To identify the minimal cost car configuration, the TCO are used in the following to evaluate the overall cost efficiency. Thus, the objective function of this optimization problem can be expressed as:

$\min T C O=f\left(E_{B a t}, Y_{n}\left(D_{n}\right), Z\right)$

where $E_{B a t}$ equals the total nominal battery capacity in kWh (including the oversizing due to degradation). The variable $Y$ describes the individual driving behavior of the user $n$. The distributions of the daily trip lengths as well as the average driving speed are modeled as a function of the annual mileage $D_{n}$. 
$Z$ summarizes the underlying scenario assumptions, which include among others the energy prices for gasoline and electricity, as well as production cost of Li-ion batteries and the assumed life time of the car. The influence of these external factors and assumptions is discussed in detail through a sensitivity analysis in Section 4. The overall structure of the optimization problem is summarized in Fig. 1.

For hybrid electric vehicles with external grid connection, two typical operating strategies can be distinguished (Shiau et al., 2009). In charge depleting mode (CD), the car is primarily powered by electric energy from the grid. When the battery state of charge $(S O C)$ reaches a lower threshold $\left(S O C_{\min }\right)$, the hybrid vehicle is operated in charge sustaining mode (CS). Here, the combustion engine generates the energy required on board for driving in order to keep the $S O C$ nearly constant until the battery is recharged again at an electric outlet (see Fig. 2). The effective energy consumption per $\mathrm{km} e_{\text {Mix }}$ is, therefore, a combination of the corresponding $\mathrm{CD}$ and $\mathrm{CS}$ consumptions $\left(e_{C D}, e_{C S}\right)$ :

$e_{\text {Mix }}=e_{C D} w_{C D}+e_{C S}\left(1-w_{C D}\right)$

The share of driving in $\mathrm{CD}$-mode $\left(w_{C D}\right)$ depends on the electric range and the driving pattern of the individual user. To avoid degradation of the battery due to deep discharge below the lower $S O C$-limit $S O C_{\min }$ only the share $\left(1-S O C_{\min }\right)$ of the total capacity $E_{B a t}$ is regularly used for driving. Therefore, the distance $d_{B a t}$, which is the distance the car is able to cover in CD-mode, is determined by the usable energy content of the battery $E_{B a t}$ until the lower SOC limit is reached:

$d_{B a t}=\frac{E_{B a t}\left(1-S O C_{\text {min }}\right)}{e_{C D}}$

The driving pattern of a user can be described with a probability density function $h(x)$ as shown in Fig. 3. Unlike previous studies (Özdemir and Hartmann, 2012, Ernst et al., 2011, Plötz et al., 2012) differentiated trip distributions are derived in the following for varying user types $n$ based on empirical data. The distribution function specifies the composition of the annual mileage $D$ out of $N$ single trips with daily driving distance $s$ :

$D=N \int_{s} h_{n}(s) s d s$

Assuming on an average one charging per day (typically overnight) the total distance $D_{C D}$ (covered in CD operating mode) for the days, where the driving distance is lower than the $d_{B a t}$, can be computed as:

$D_{C D}=N \int_{s=0}^{d_{B a t}} h_{n}(s) s d s$

The corresponding number of trip $N_{C D}$ with a distance lower than $d_{B a t}$ kilometer is defined by:

$N_{C D}=N \int_{s=0}^{d_{B a t}} h_{n}(s) d s$
The trips $\left(N-N_{C D}\right)$ with a daily driving distance $s>d_{B a t}$ are covered in mixed operating modes. In the first part of the journey, the car is operated in CD-mode until the battery reaches its minimum state of charge after $d_{B a t}$ kilometers; the remaining distance is completed by CS-mode (see Fig. 2). So, the average share of $C D$-driving $\left(w_{C D}\right)$ in the course of one year can be described by:

$w_{C D}\left(d_{B a t}\right)=\frac{D_{C D}+\left(N-N_{C D}\right) d_{B a t}}{D}$

\section{Model and data}

\subsection{Vehicle setup and energy consumption}

To analyze the energy consumption of the examined powertrain concepts, the DLR Modelica library AlternativeVehicles (Hülsebusch et al., 2009) is used in this study. The simulation software contains a large set of parameterized drivetrain components (e.g. electric drives, transmissions, batteries) which allow to model different powertrain architectures and simulate the dynamic system behavior in various driving cycles.

This assessment focuses on two representative powertrain concepts. The PHEV is designed as a parallel hybrid electric vehicle which employs a torque-adding electric motor, flange-mounted to a six-speed automatic gear and two clutches that allow decoupling the combustion engine. The EREV represents a serial hybrid architecture with a central electric motor and a single speed transmission. The combustion engine serves as a range extender module that generates energy in case of low battery state of charge and has no direct connection with the wheels. Both EVs use a Li-ion battery in high energy configuration as electrical energy storage. For comparison reasons, a conventional car with ICE (gasoline, spark ignition (SI) engine) is also included in the study. The setup of the simulated vehicles corresponds to the average configuration of a midsize passenger car based on an analysis of the German auto market (ADAC, 2010). The basic technical parameters of the reference vehicles are summarized in Table 1. All three cars in the assessment show a similar acceleration performance (between 8 to $9.5 \mathrm{~s}$ to accelerate from 0 to $100 \mathrm{~km} / \mathrm{h}$ ).

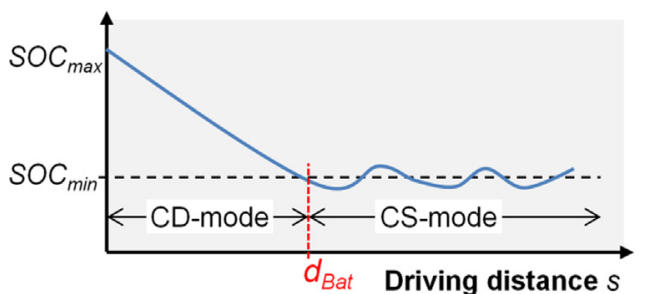

Fig. 2. Battery state of charge in $C D$ and CS-mode (illustrative according to Shiau et al. (2009)).

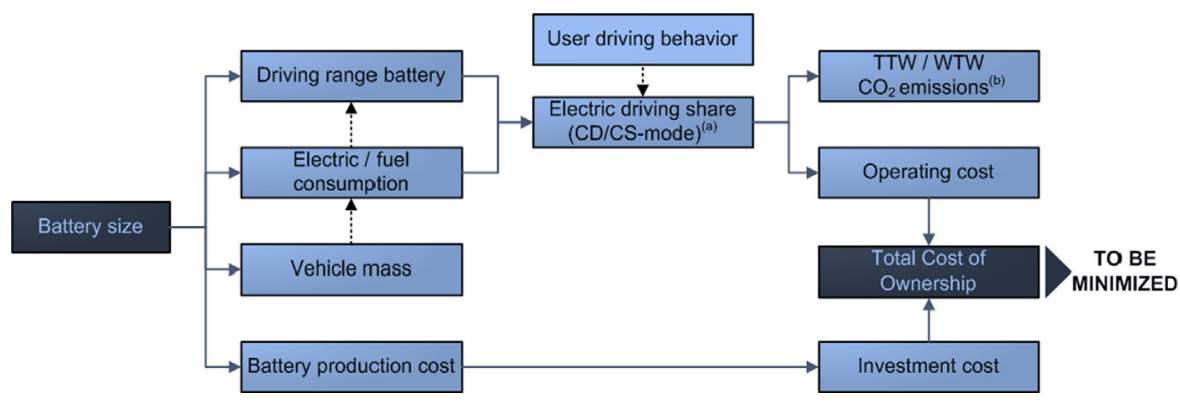

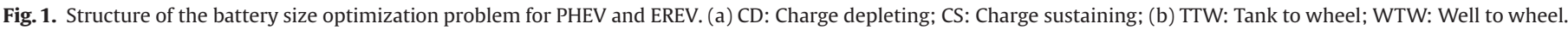



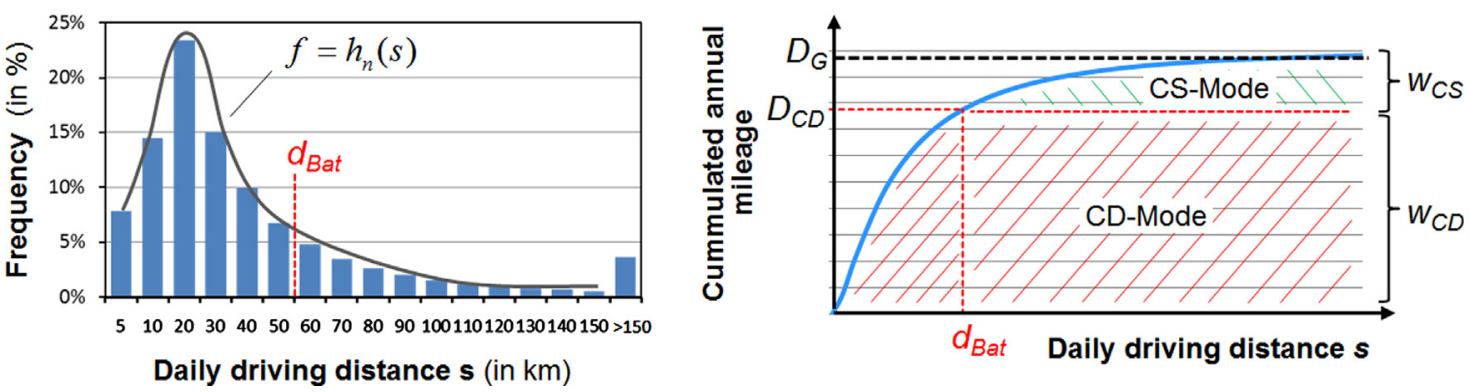

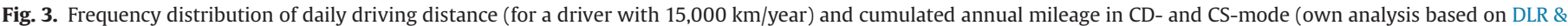
Infas, 2010).

However, due to the parallel hybrid architecture, the PHEV has some performance advantages if both, combustion engine and electric motor, are used in combination.

The New European Driving Cycle (NEDC) is applied as standardized driving cycle to compare the energy efficiency of the selected powertrain concepts. In addition, real-world fuel consumption in urban and extra urban driving is assessed by taking the average power demand for auxiliaries (as specified in Table 1) into account. The simulation results of the reference vehicles separated in $C D$ and $C S$ mode are presented in Table 2. The combined NEDC values and $\mathrm{CO}_{2}$ emissions are calculated according to the official EU Directive 70/220/EWG and UNECE Rule No. 101 (Rousseau et al., 2012).

In the following analysis, the battery capacity of PHEV and EREV are considered as variable. A change of battery size also affects the vehicle mass and subsequently the energy consumption. According to the methodology applied in Redelbach et al. (2012a), the adjusted vehicle weight is modeled as

$m=m_{0}+\frac{\Delta E_{\text {Bat }}}{\rho_{\text {Bat }}}(1+\varphi)$

where, $m_{0}$ denotes the mass of the reference vehicle and $\rho_{\text {Bat }}$ is the gravimetric energy density of the battery pack. The structural weight factor $\varphi$ is assumed to be 0.5 for midsize passenger cars in accordance with an analysis of Malen and Reddy (2007). It describes the secondary mass effects for the required modification in the vehicle body and chassis, if extra battery weight is added (Shiau et al., 2009). To quantify the sensitivity of the energy consumption regarding chances in vehicle mass, a set of parameter variations has been performed and analyzed. Starting from the reference configuration defined in Table 1 , the total mass of the examined vehicle concepts is changed in discrete steps of $100 \mathrm{~kg}$ while all other parameters are kept constant. The observed effects on the energy consumption of PHEV and EREV are plotted in Fig. 4. The simulation results show a linear relationship that can be described as follows:

$e=e_{0}+\varepsilon_{m}\left(m-m_{0}\right)$

with the mass influence factor $\varepsilon_{m}=\Delta e / \Delta m$. For simplification $\varepsilon_{m}$ is assumed to be identical in CD and CS model. For a detailed analysis of the weight effects on energy consumption and related mobility costs for different electrified powertrain concepts see Redelbach et al. (2012a).

\subsection{Total cost of ownership model}

The applied TCO model covers all types of expenses accruing for a vehicle owner (in EUR2010) including investment costs as well as operating costs (e.g., fuel/energy, vehicle tax, general/exhaust inspection, maintenance, and repair). The annual mileage, vehicle
Table 1

Definition of technical parameters for the analyzed medium size passenger cars with different powertrains (based on (ADAC, 2010, Wallentowitz, 2011, Braess, 2012, Mock et al., 2009)).

\begin{tabular}{|c|c|c|c|c|}
\hline $\begin{array}{l}\text { Parameter } \\
\text { Vehicle architecture }\end{array}$ & Unit & $\begin{array}{l}\text { ICE } \\
\text { Gasoline SI- } \\
\text { engine, direct } \\
\text { ignition, } \\
\text { 2-wheel drive } \\
\text { (identical for } \\
\text { all), 6-speed } \\
\text { automatic } \\
\text { transmission }\end{array}$ & $\begin{array}{l}\text { PHEV } \\
\text { Parallel hybrid } \\
\text { with } 2 \text { clutches, } \\
\text { 6-speed } \\
\text { automatic } \\
\text { transmission } \\
\text { with torque- } \\
\text { adding electric } \\
\text { motor external } \\
\text { charge unit }\end{array}$ & $\begin{array}{l}\text { EREV } \\
\text { Series hybrid } \\
\text { with gasoline } \\
\text { engine as } \\
\text { range } \\
\text { extender, } \\
\text { single speed } \\
\text { gear, external } \\
\text { charge unit }\end{array}$ \\
\hline $\begin{array}{l}\text { Power (combustion } \\
\text { engine) }\end{array}$ & $k W$ & 100 & 75 & 50 \\
\hline $\begin{array}{c}\text { Power (electric } \\
\text { motor) }\end{array}$ & $k W$ & - & 50 & 100 \\
\hline $\begin{array}{c}\text { Traction battery } \\
\text { capacity }^{\mathrm{a}}\end{array}$ & $k W h$ & - & 5 & 15 \\
\hline $\begin{array}{l}\text { Driving range in CD- } \\
\text { mode }^{\mathrm{a}}\end{array}$ & $\mathrm{km}$ & - & 48 & 77 \\
\hline Curb weight & $\mathrm{kg}$ & 1400 & 1510 & 1580 \\
\hline Frontal area & $m^{2}$ & 2.2 & & \\
\hline Drag coefficient & - & 0.28 & & \\
\hline $\begin{array}{c}\text { Rolling resistance } \\
\text { coefficient }\end{array}$ & - & 0.1 & & \\
\hline $\begin{array}{l}\text { Average energy } \\
\text { consumption for } \\
\text { auxiliaries }\end{array}$ & $W$ & 700 & 900 & 1100 \\
\hline
\end{tabular}

a The battery capacity and the corresponding electric range are variable in the following analyses. The values in the table indicate the nominal battery capacity of the reference vehicle.

holding period and use characteristics (i.e. share of electric driving) are adjustable to facilitate the economic comparison for different types of users as well as to perform sensitivity analyses. Fig. 5 shows an overview of the general structure of the TCO model. For a more detailed description of the model see Redelbach et al. (2012b), Propfe et al. (2012b) and Redelbach et al. (2013).

In this study, a typical life time of 12 years is assumed for the TCO calculation similar to Özdemir and Hartmann (2012). The running costs over time are discounted with an internal interest rate $i$ of $5 \%$ p.a. Furthermore, it is assumed that the vehicle does not have any residual value at the end of its lifetime. So the TCO calculation $\left(C_{T C O}\right)$ can be described as net present value in an aggregated form as:

$C_{\text {TCO }}=C_{\text {Invest }}+\sum_{t=1}^{12} \frac{\left(C_{\text {Energy }, t}+C_{\text {Maintanance }, t}+C_{\text {Other }, t}\right)}{(1+i)^{t}}$ 
Table 2

Energy consumption of reference medium size passenger cars with different powertrains (based on simulation results with DLR AlternativeVehicles library).

\begin{tabular}{|c|c|c|c|}
\hline Fuel (gasoline) consumption & $\begin{array}{l}\text { ICE }^{\mathrm{a}} \\
l / 100 \mathrm{~km}\end{array}$ & $\begin{array}{l}\text { PHEV }^{\mathrm{b}} \\
l / 100 \mathrm{~km}(C S / C D)\end{array}$ & $\begin{array}{l}\text { EREV }^{\mathrm{b}} \\
l / 100 \mathrm{~km}(C S / C D)\end{array}$ \\
\hline NEDC & 6.8 & 3.0 & 1.1 \\
\hline Urban (real-world) & 10.8 & $6.7 / 0.0$ & $6.4 / 0.0$ \\
\hline Extra urban (real-world) & 7.0 & 5.6 / 4.1 & $5.8 / 0.0$ \\
\hline Electricity consumption (from the grid) & & $W h / k m(C D)$ & $W h / k m(C D)$ \\
\hline NEDC & - & 30 & 91 \\
\hline Urban (real-world) & - & 157 & 162 \\
\hline Extra urban (real-world) & - & 33 & 152 \\
\hline $\mathbf{C O}_{2}$ emissions (in $\mathrm{g} / \mathrm{km}$, Tank-to-wheel, NEDC) & 157 & 71 & 26 \\
\hline
\end{tabular}

${ }^{a}$ Values in the table are for the reference year 2010. An average efficiency improvement of $2 \%$ per year is assumed for ICE fuel consumption between 2010 and 2020.

${ }^{\mathrm{b}}$ Energy consumption of reference configuration, changes in vehicle mass (due to variations of battery size) effect energy consumption.

Table 3

Assumed production cost in EUR 2010 of midsize cars with different powertrains in Germany for the year 2020.

\begin{tabular}{|c|c|c|c|c|}
\hline Production cost (in EUR 2010 $_{\text {) }}$ & ICE & PHEV & EREV & Source \\
\hline Combustion engine (SI) & 2720 & 2,040 & 1360 & (CONCAWE et al., 2011) \\
\hline Electric motor & - & 640 & 940 & DLR cost model (Braun, 2012) \\
\hline Power electronics (incl. charging unit) & - & 980 & 1370 & DLR cost model (Braun, 2012) \\
\hline Traction battery & - & 1650 & 4050 & DLR cost model (Kroll, 2011) \\
\hline Other powertrain components (incl. transmissions, tank, etc.) & 2730 & 2560 & 2300 & Analysis based on (McKinsey \& Company and RWTH Aachen, 2011) \\
\hline Rest of the vehicle & 11,280 & & & Analysis based on (ADAC, 2010, KBA, 2011) \\
\hline Total production cost of the vehicle & 16,730 & 19,150 & 21,300 & \\
\hline
\end{tabular}

a Battery cost for the defined reference vehicle in Table 1 (battery size of $5 \mathrm{kWh}$ in PHEV and $15 \mathrm{kWh}$ in EREV) and an assumed plant capacity of 100,000 units/a. In the following, the battery size and resulting costs are taken as a variable and will be optimized.

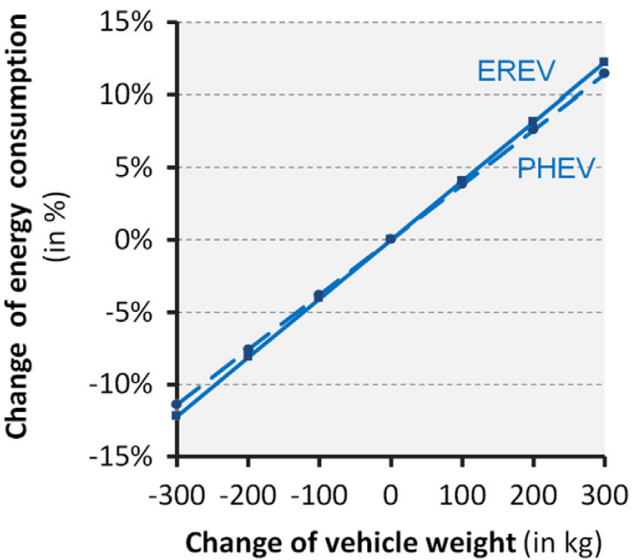

Fig. 4. Change of energy consumption relative to reference vehicle for PHEV and EREV as a function of vehicle weight (Redelbach et al. 2012a).

where $C_{\text {Invest }}$ is the purchase price of the vehicle, $C_{\text {Energy }}$ is the annual energy cost for fuel and grid electricity, $C_{\text {Maintanance }}$ is the annual maintenance and costs for the vehicle owner, ${ }^{1} C_{\text {other }}$ is the sum of vehicle tax (based on engine capacity and emissions) and expenses for mandatory general and exhaust inspection in Germany, $i$ is the calculatory interest rate and $t$ is the operation time in years.

To project the future development of the production cost for the core components of the electric drivetrain (traction battery, electric motor and power electronics) specialized models, which have been developed at the DLR Institute of Vehicle Concepts, are applied (Kroll, 2011, Braun, 2012, Propfe et al., 2012a). The battery

\footnotetext{
${ }^{1}$ As maintenance costs are not expected to affect the optimal battery size, they are not considered in the following analysis for simplicity reasons.
}

cost model allows estimating cell, module, and pack production cost for the most important Li-ion chemistries as a function of the production volume. In this assessment, lithium nickel manganese cobalt oxide (NMC) has been selected as cathode material for the high-energy storage with a learning rate of $86 \%$ (i.e. with a doubling of output the average production cost decrease by $14 \%$ due to economies of scales). The resulting costs in $\mathrm{EUR}_{2010} / \mathrm{kWh}$ for production volumes of 10,000 and 100,000 packs per year are plotted in Fig. 6 for varying battery capacities. The resulting battery costs for a production plant with a capacity of 100,000 packs per year (which are assumed to be reached in 2020) are about 330 EUR $_{2010} / \mathrm{kWh}$ for $5 \mathrm{kWh}$ battery pack and $270 \mathrm{EUR}_{2010}$ $\mathrm{kWh}$ for $15 \mathrm{kWh}$ pack. This is in line with other cost projections given in the literature which estimate battery costs in the range between 200 and $420 \mathrm{EUR} / \mathrm{kW}$ for the year 2020 (Özdemir and Hartmann, 2012, Fraunhofer, 2013). The assumed production cost of the other powertrain components are summarized in Table 3. The rest of the car (e.g. body, chassis, interior, exterior) is assumed to be identical for all analyzed vehicle concepts. To estimate the investment cost of the car buyer an average margin of $35 \%$ (accounting for indirect costs and profit margin of the OEM based on Mock (2010)) and VAT of 19\% is added.

The annual energy costs for the vehicle owner $\left(C_{\text {Energy }}\right)$ are determined by the effective energy consumption (in blended mode) and the corresponding market prices for electricity $\left(p_{E}\right)$ and fuel $\left(p_{F}\right)$ in EUR $2010 / a$ :

$C_{\text {Energy }}=D\left(e_{C D} w_{C D} p_{E}+e_{C S}\left(1-w_{C D}\right) p_{F}\right)$

where $w_{C D}$ indicates the share of electric driving in $C D$ mode (estimated according to Eq. (7) as a function of the driver's annual mileage). 


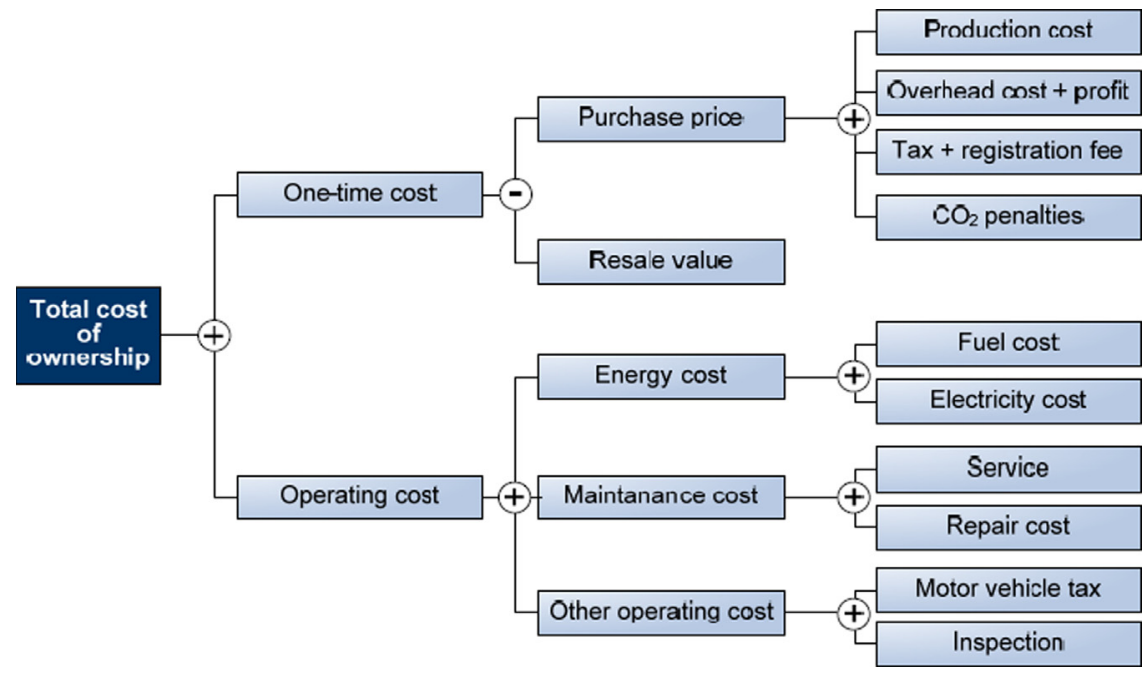

Fig. 5. General structure of the TCO model (Redelbach et al. 2012b).

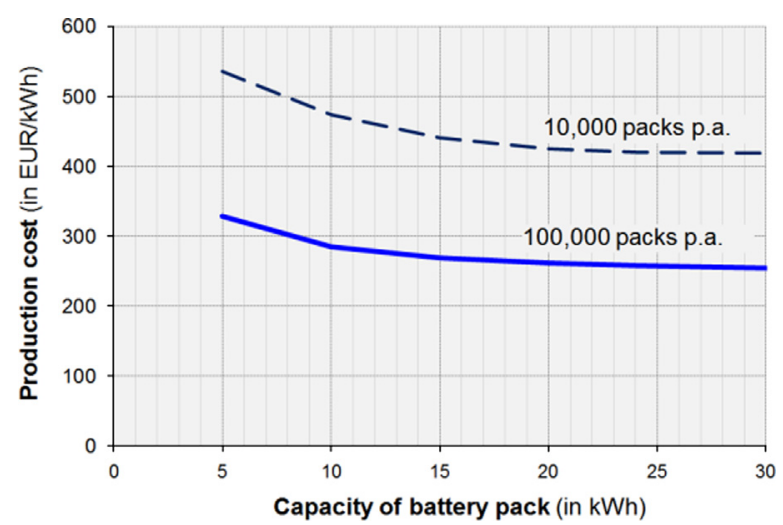

Fig. 6. Production cost of high energy batteries as a function of production volume and pack size.

For other external factors (e.g. gasoline and electricity prices), which influence the TCO analysis, representative assumptions have been made to reflect the situation in the German car market in 2020. An overview about the most relevant input parameters for the optimization problem is provided in Table 4. In the sensitivity analysis in Section 4, these assumptions are varied systematically.

\subsection{Driving behavior}

The mobility behavior within the population is extremely diverse. While drivers with low annual mileage (e.g. 7500 km/a) cover a distance of less than $20 \mathrm{~km}$ on 201 days in a year, which corresponds to a share of 55\% (201 d/365 d). This share is less than $30 \%$ ( $110 \mathrm{~d} / \mathrm{a}$ ) for frequent drivers (e.g. 30,000 km/a) (see Fig. 7). To model the observed heterogeneity across users and the resulting effects on the battery optimization problem realistically, typical driving patterns are derived based on empirical data. The national travel survey Mobility in Germany (MiD) (DLR \& Infas, 2010), which characterizes the detailed mobility behavior of more than 50,000 German households in 2008, is used as primary data source. For the following analysis, three representative cases are selected: user B has an annual mileage of $15,000 \mathrm{~km} / \mathrm{a}$, which is close to the German average. user $\mathrm{C}$, as a frequent driver, travels double of this distance $(30,000 \mathrm{~km} / \mathrm{a})$ and user A only half of this distance $(7500 \mathrm{~km} / \mathrm{a})$. For all three drivers, a typical frequency distribution of the daily driving distance $h(s)$ is determined based on MiD data and described mathematically with a log normal fit. With $h(s)$ and Eqs. (3)-(7) the share of driving in CD operating mode can be evaluated as a function of the electric range. As plotted in Fig. $8 w_{C D}$ grows with degreasing gradient over $d_{B a t}$. This analysis indicates that as the mileage gets higher, the resulting $\mathrm{CD}$-share will be lower. So, given an electric range of $40 \mathrm{~km}$, user A would drive $68 \%$ of his travel distance in CD-mode, user C only $51 \%$.

In addition, the MiD data is also used to identify the average driving speed of different user types. The empirical data shows a relationship between the trip distance and mean speed (calculated as the ratio of trip length and travel time). People who usually travel longer distances tend to spend more time on motorways with a higher average velocity than short distance drivers. In addition, the place of residence also has a significant influence on the driving speed as shown in Fig. 9. On short trips, people from densely populated urban and metropolitan areas show a significant lower driving speed than people from rural areas due to frequent stop-and-go traffic within cities. With increasing trip distance ( $>25 \mathrm{~km}$ ), the average driving speed of users with rural and urban place of residence converge (see Fig. 9).

To take these differences in driving style into account, the mix of urban $\left(w_{\text {urban }}\right)$ and extra-urban driving $\left(w_{\text {extra-urban }}\right)$ in the model is adjusted in a way that the weighted average of the driving speed in the simulated driving cycles ( $\left.v_{\text {urban }}, v_{\text {extra-urban }}\right)$ equals the statistically observed mean speed $\left(v_{n, \text { mean }}\right)$ of user $n$ :

$$
\begin{aligned}
v_{\text {mean }, n}= & w_{\text {urban }, n} v_{\text {urban }}+w_{\text {extra }- \text { urban }, n} v_{\text {extra }- \text { urban }} \text { with } \\
& w_{\text {urban }, n}+w_{\text {extra }- \text { urban }, n}=1
\end{aligned}
$$

So the share of urban driving of user $n$ can be estimated by:

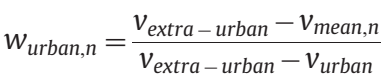

In the following the average energy consumption of the vehicle driven by user $n$ is calculated by combining the simulated energy consumption in urban and extra-urban drive cycles (Table 2) with the determined individual weighting for user $n$ :

$e_{\text {combined }, n}=e_{\text {urban }} w_{\text {urban }, n}+e_{\text {extra-urban }, n}\left(1-w_{\text {urban }, n}\right)$

For the three selected user types assessed in this study, this method results in urban and extra urban driving shares of about $53 \%$ and $47 \%$ for user A, $40 \%$ and $60 \%$ for user B and $22 \%$ and $78 \%$ for user $C$, respectively. 
Table 4

Parameters for baseline scenario in year 2020.

\begin{tabular}{|c|c|c|c|}
\hline Input parameter & Unit & Value & Source \\
\hline Oil price & $\mathrm{USD}_{2011} / \mathrm{bbl}$ & 118 & (IEA, 2011) Current policy scenario \\
\hline Gasoline retail price & $\mathrm{EUR}_{2010} / 1$ & 1.62 & Based on historical regression between oil and gasoline price (ADAC, 2013) \\
\hline Electricity retail price & $\mathrm{EUR}_{2010} / \mathrm{kWh}$ & 0.27 & Own calculation based on BMU (2012) \\
\hline Life time / holding period & a & 12 & Assumption based on (Özdemir and Hartmann, 2012) \\
\hline Interest rate & $\%$ & 5 & Assumption based on (Fraunhofer, 2013) \\
\hline Battery production plant capacity & Packs/a & 100,000 & Model assumption based on (NPE, 2011) \\
\hline Battery energy density (pack) & $\mathrm{kWh} / \mathrm{kg}$ & 0.1 & (den Boer et al., 2013) \\
\hline Minimum SOC & $\%$ & 20 & (Özdemir and Hartmann, 2012, Fraunhofer ISI, 2013) \\
\hline $\mathrm{CO}_{2}$ emissions gasoline (TTW) & $\mathrm{g} / \mathrm{MJ}$ & 73.3 & (CONCAWE et al., 2011) \\
\hline $\mathrm{CO}_{2}$ emissions gasoline (WTT) & $\mathrm{g} / \mathrm{MJ}$ & 7.4 & (SULTAN, 2010) \\
\hline $\mathrm{CO}_{2}$ emissions electricity (WTT) & $\mathrm{g} / \mathrm{MJ}$ & 75.2 & (BMU, 2012) \\
\hline
\end{tabular}

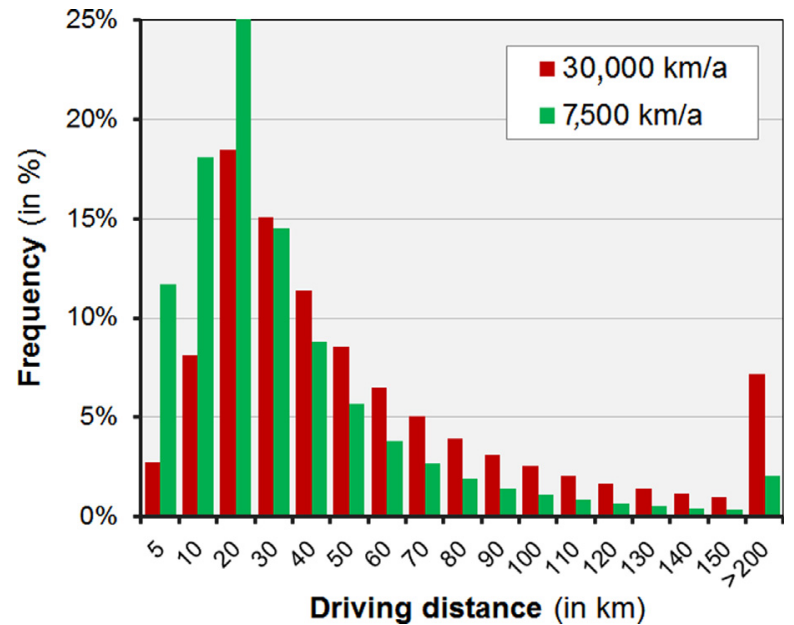

Fig. 7. Distribution of the daily driving distance for users with low and high annual mileage (own analysis based on MiD data).

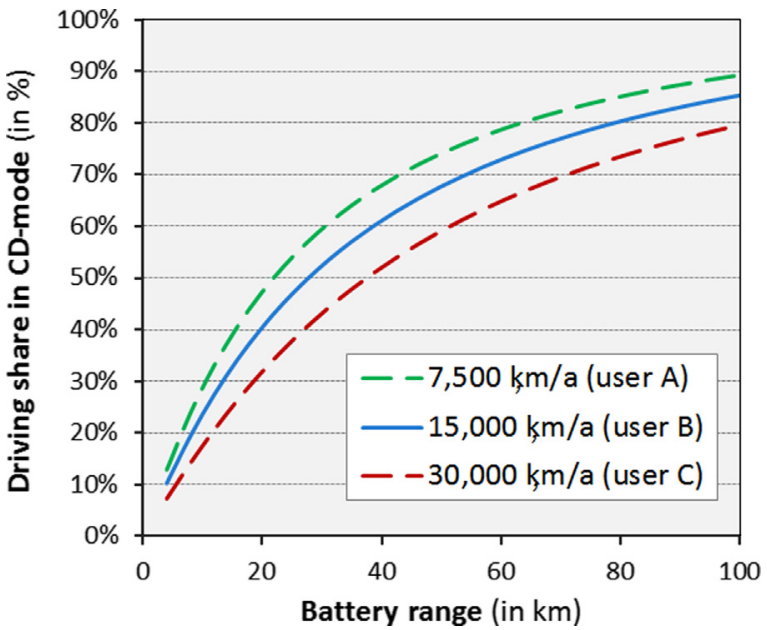

Fig. 8. Average annual $C D$-driving share $\left(w_{C D}\right)$ as a function of electric battery range $\left(d_{\text {Bat }}\right)$.

\section{Results and discussion}

In the following, the effect of the battery size on energy consumption and TCO are analyzed and presented in detail for the EREV case. The analysis for the PHEV follows the same methodology. For PHEVs, only relevant differences will be highlighted in the text.

The average electricity consumption from the grid and the average gasoline fuel consumption for different daily driving

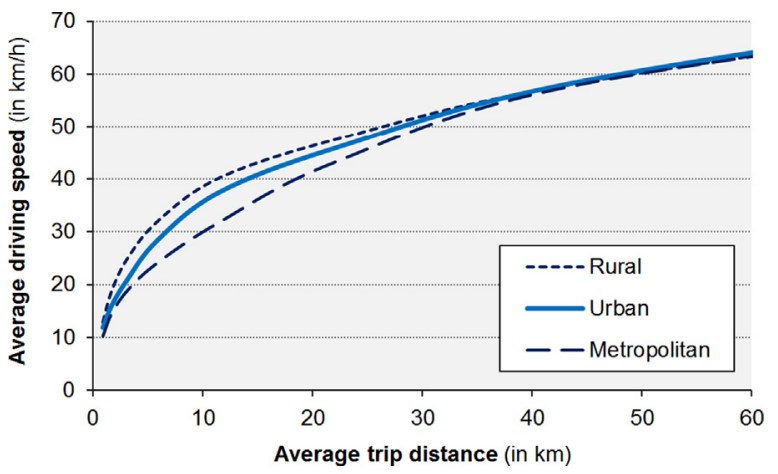

Fig. 9. Average driving speed in Germany as a function of average trip distance and place of residence (own analysis based on MiD data, (Rousseau et al., 2012)).

distances are shown in Fig. 10 (left side) for an EREV driver with an annual mileage of $15,000 \mathrm{~km} / \mathrm{a}$ (user B). The average electricity consumption, which is about $15 \mathrm{kWh} / 100 \mathrm{~km}$ for the CD-mode, is constant, if the driving distance is shorter than the $d_{\text {Bat }}$. The traction energy is provided mainly by an ICE in CS-mode, so the average electricity consumption over the whole driving distance decreases, where the average fuel consumption is increasing. The resulting final energy consumption of the EREV (sum of electricity and gasoline fuel) is shown in Fig. 10 (right side) as a function of battery size for a user with an annual $15,000 \mathrm{~km}$. As expected, the average final energy consumption in $\mathrm{MJ} / 100 \mathrm{~km}$ reduces as the battery's driving range increases due to the fact that the electric motor has a higher efficiency than the ICE. The increased battery weight for longer battery driving range, which requires higher traction energy, has been taken into account in this analysis. The calculated energy consumption is ca. $90 \mathrm{MJ} / 100 \mathrm{~km}$ for a battery driving range of $61 \mathrm{~km}$, which corresponds to the range of Chevrolet Volt-EREV. For this case, the share of consumption for electricity from grid and fuel are calculated as $45 \%$ and $55 \%$, respectively.

The results for energy consumption of the PHEV (Fig. 11) are significantly higher compared to the EREV especially for higher battery sizes. The calculated energy consumption is ca. $135 \mathrm{MJ} /$ $100 \mathrm{~km}$ for a battery size of $5 \mathrm{kWh}$, which corresponds to the setup of Toyota Prius-PHEV. For this case, the share of consumption for electricity from grid and fuel are calculated as $15 \%$ and $85 \%$, respectively.

The combined energy cost for electricity and fuel $\left(C_{\text {Energy }}\right)$ are calculated according to Eq. (11) based on the energy consumption and the assumed prices of the energy carriers (see Table 4). The resulting costs from the TCO model are plotted in Fig. 12 as a function of battery capacity for the three selected user types. The analysis shows two different effects. First, the energy cost decrease with growing battery size due to the higher share of electric driving 

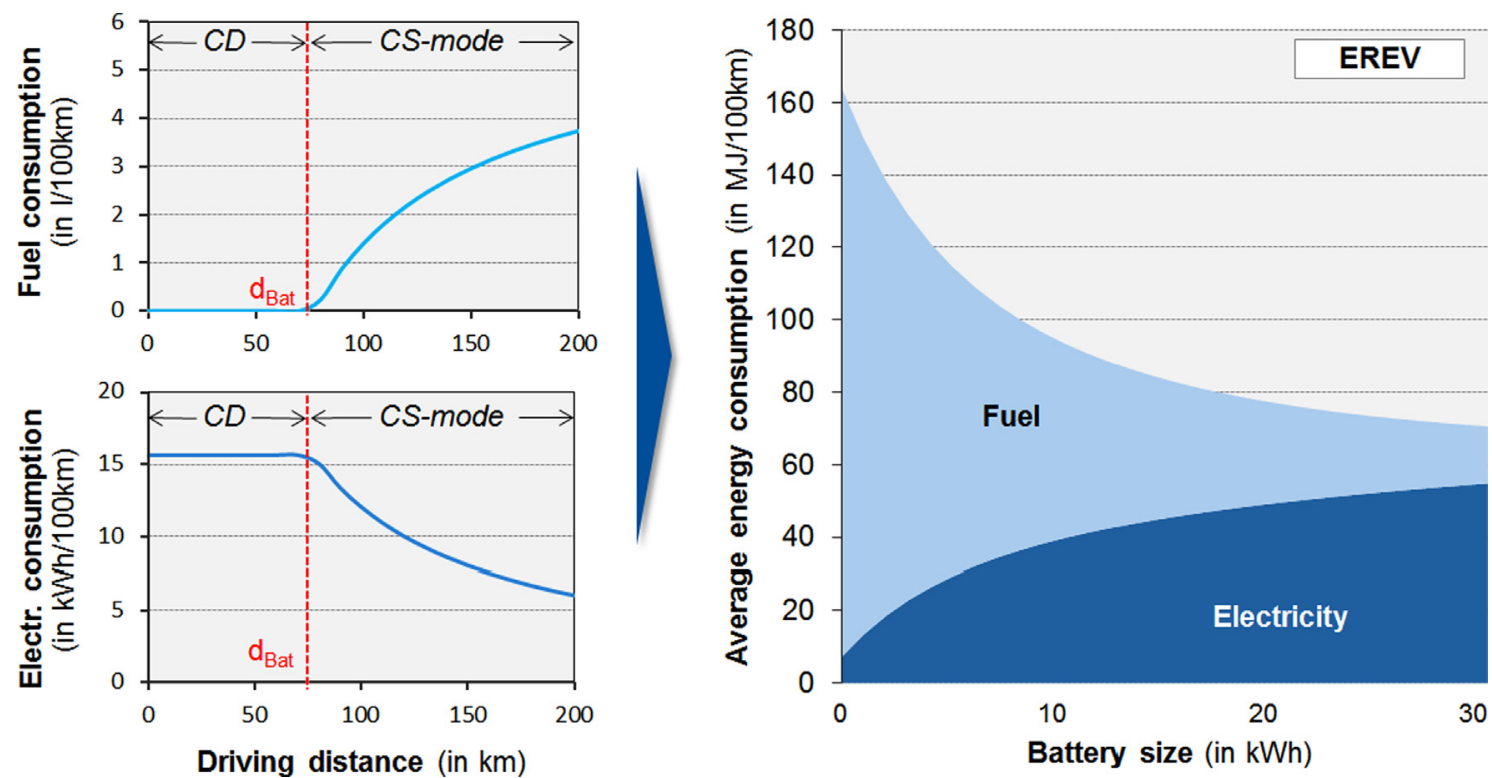

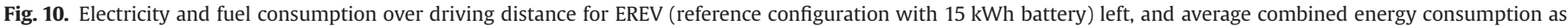
a function of battery size for user B $(15,000 \mathrm{~km} / \mathrm{a})$ right.
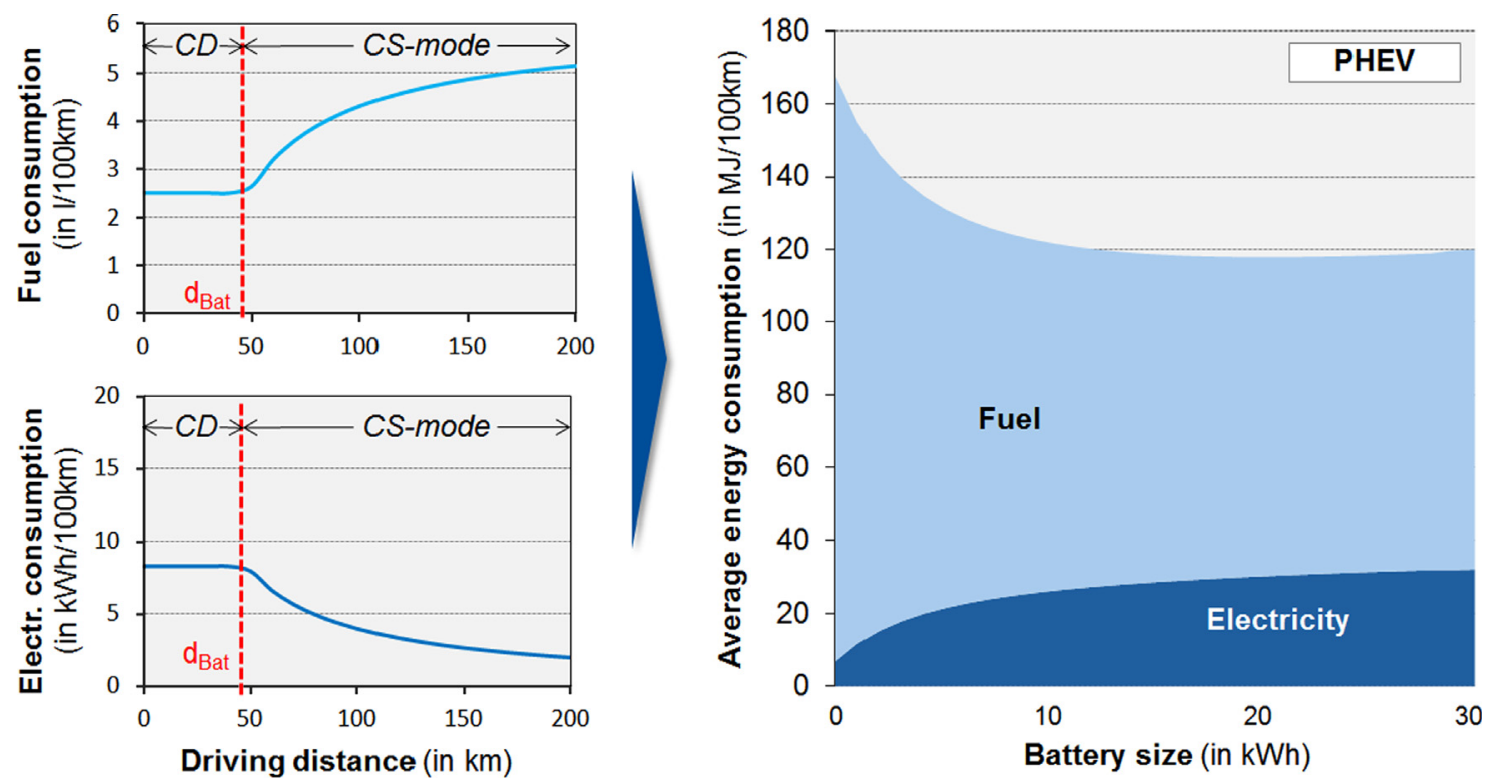

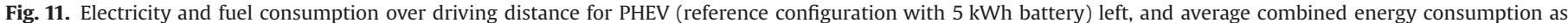
a function of battery size for user B $(15,000 \mathrm{~km} / \mathrm{a})$ right.

for all users. The gradient of the curve declines as the additional savings get small for capacities over $15 \mathrm{kWh}$. Second, for a given battery size the specific energy costs (in $\mathrm{EURc}_{2010} / \mathrm{km}$ ) rise with the mileage of the user. For example, with an EREV battery size of $10 \mathrm{kWh}$, energy costs are $4.5 \mathrm{EURc}_{2010} / \mathrm{km}$ and $5.0 \mathrm{EURc}_{2010} / \mathrm{km}$ for annual mileages of $7500 \mathrm{~km}$ and $30,000 \mathrm{~km}$, respectively. This effect is caused by the observed differences in trip distribution and driving speed (see Figs. 7 and 9). Frequent travelers have a higher share of long distance trips and on an average drive faster, both of which result in a lower share of driving in CD-mode. Nevertheless, user C with $30,000 \mathrm{~km}$ per year profits most in absolute terms by installing a larger battery size. Its annual energy costs are reduced by 250 EUR, when the driver chooses $10 \mathrm{kWh}$ instead of $5 \mathrm{kWh}$ battery. In case of user A, the equivalent savings are only 60 EUR per year.

Although PHEVs have similar results, the energy costs are at a slightly higher level. The energy costs for a battery size of $10 \mathrm{kWh}$

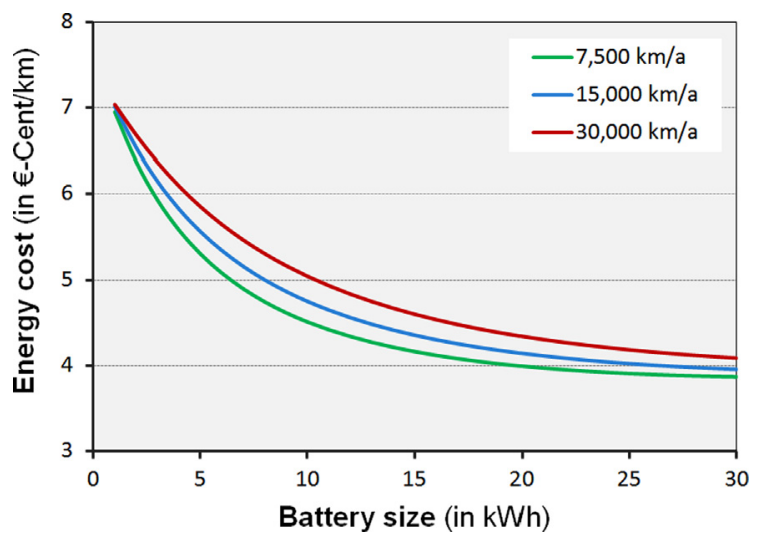

Fig. 12. Energy (electricity and fuel) cost in $\mathrm{EURc}_{2010} / \mathrm{km}$ of EREV as a function of battery size and annual mileage. 

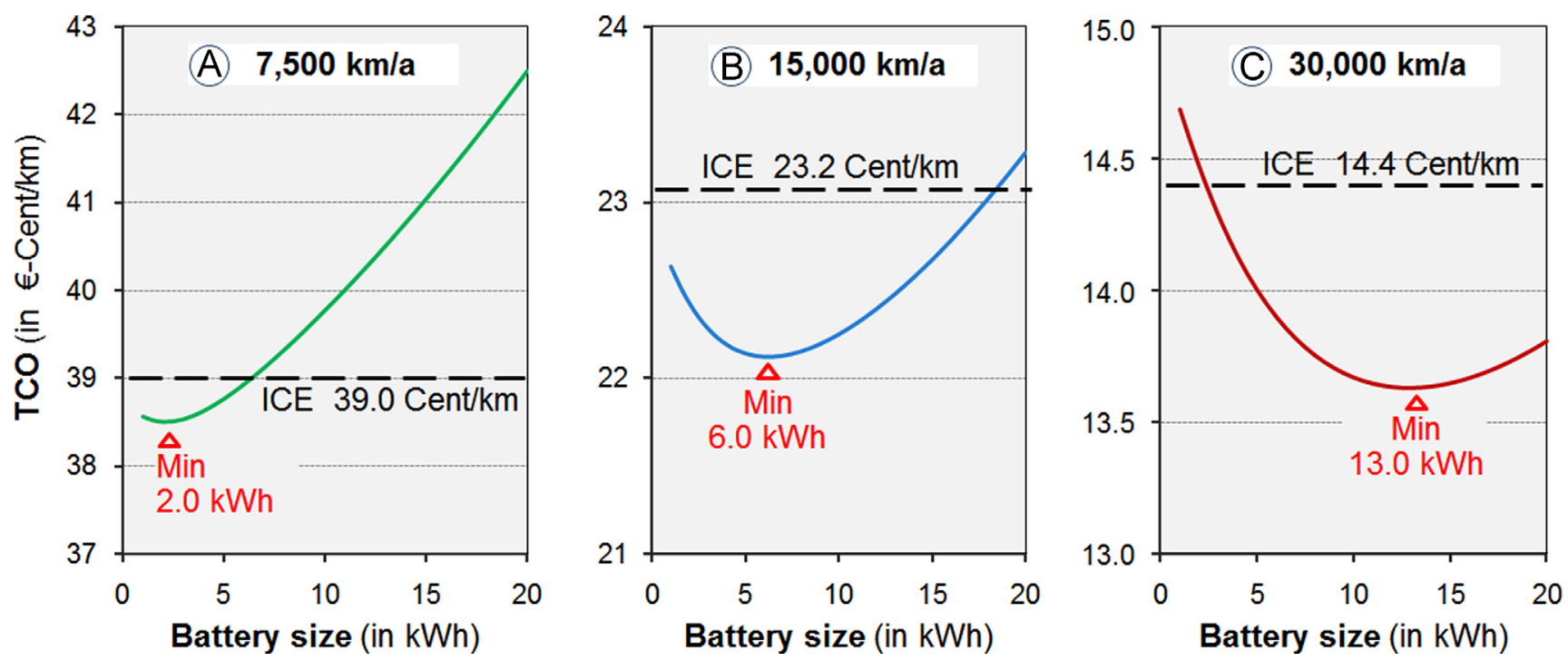

Fig. 13. $T C O$ in $E \mathrm{URc}_{2010} / \mathrm{km}$ of EREV as a function of battery size for users with different annual mileages.

are $5.1 \mathrm{EURc}_{2010} / \mathrm{km}$ and $5.8 \mathrm{EURc}_{2010} / \mathrm{km}$ for annual mileages of $7500 \mathrm{~km}$ and $30,000 \mathrm{~km}$, respectively. Increased energy costs of PHEVs compared to EREVs are due to the higher overall energy consumption and higher share of CS-mode by PHEVs.

The total cost of ownership (TCO) is analyzed for the different user types (see section 3.3) and shown in Fig. 13 depending on the battery size for EREV. For drivers A, B and C, least costs are achieved with the battery sizes of $2.0,6.0$ and $13.0 \mathrm{kWh}$, respectively. These battery sizes correspond to 8,24 and $51 \mathrm{~km}$ of electrical range depending on the individual driving profiles of the users A, B and C, respectively. The comparison of the minimum TCO for the optimized battery size with the conventional ICE vehicle shows that the EREV might be a cost saving technology for all the driver types in the year 2020 .

The TCO-curves are similar for the PHEVs with the exception that the optimal battery sizes are smaller (1.5, 3.5 and $5.0 \mathrm{kWh}$ in case of user A, B and C). The reason for the difference is again the higher share of CS-mode by PHEVs.

In a comprehensive sensitivity analysis the assumed values for gasoline price, life time, energy density of the battery, interest rate, battery cost and electricity price are varied and the resulting change in the optimal battery size for EREV driver B (15,000 km/a) is plotted in Fig. 14. It can be seen that among the varied parameters gasoline prices have the highest impact on the results. An increase in the gasoline prices by $30 \%$ causes a change in the optimal battery capacity of more than $+50 \%$. The optimal battery size is also relavtively sensitive to variations of the electricity prices and battery cost. If these input parameters increases by $30 \%$ (ceteris paribus), the optimal battery capacity would be approximatly 30\% lower than determined before.

As gasoline and electricity prices are decisive for the optimal battery size (see Fig. 14), a more detailed parameter variation is performed for these parameters. The effect of increasing gasoline and electricity prices about $25 \%$ is shown in Fig. 15 for PHEV (left side) and EREV (right side) for different annual mileages. For example, the PHEV driver $C$ (with an annual mileage of $30,000 \mathrm{~km} / \mathrm{a}$ ) has the optimal battery size of $5.0 \mathrm{kWh}$ under assumed gasoline and electricity prices. Increasing gasoline and electricity prices by $25 \%$ would result in an optimal battery size of ca. $6.4 \mathrm{kWh}$ (increase of $28 \%$ ) and $4.2 \mathrm{kWh}$ (decrease of 16\%), respectively. A similar trend can also be seen by EREV.

A comparison of the results in the present study with the existing literature shows that the optimum battery size (about $4 \mathrm{kWh}$ in this study) of PHEVs for an average German driver (driver B) matches

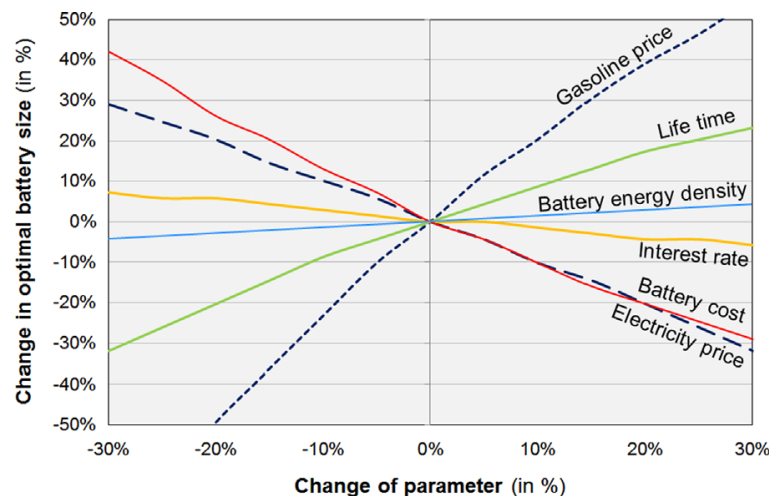

Fig. 14. Variation of relevant input parameters and resulting effect on cost optimal battery size (EREV driver B).

well with the results of Özdemir and Hartmann (2012) and Ernst et al. (2011). On the other hand, the analytically derived battery size determined by Plötz et al. (2012) seems to be significantly different for an average driver in Germany ( $>10 \mathrm{kWh}$ ). The situation for other driver types (A and C) and EREV are not analyzed in the mentioned literature. The results in the present study show that there are significant differences for the optimal battery size for different configurations (EREV vs. PHEV) and for different driving profiles (A, B and C). For an average German driver (driver B), the optimal battery size is $50 \%$ higher ( $6 \mathrm{kWh}$ instead of $4 \mathrm{kWh}$ ) for the serial hybrid architecture compared to the parallel powertrain design (see Fig. 15). On the other hand, for a given configuration (e.g. EREV), the optimal battery size differs significantly depending on the driving profile. While driver A with low annual mileage (7500 km/a) should choose a very small battery capacity of about $2 \mathrm{kWh}$, frequent driver $\mathrm{C}(30,000 \mathrm{~km} / \mathrm{a})$ should decide for a considerably higher battery size of about $13 \mathrm{kWh}$ in order to minimize his total cost of ownership. Therefore, it is especially important to take the driving profile of the customers into account in order to find the cost efficient powertrain configuration.

In today's market there are only few PHEV models available which have entered mass production. The Toyota Prius Plug-in has a battery capacity of $5.2 \mathrm{kWh}$ which is in line with the determined cost optimal battery size for users with medium mileages. The battery of the Chevrolet Volt ( $16 \mathrm{kWh})$ and the Porsche Panamera PHEV (9.4 kWh) are relatively large compared to the study results. These configurations might be motivated in the target customer 

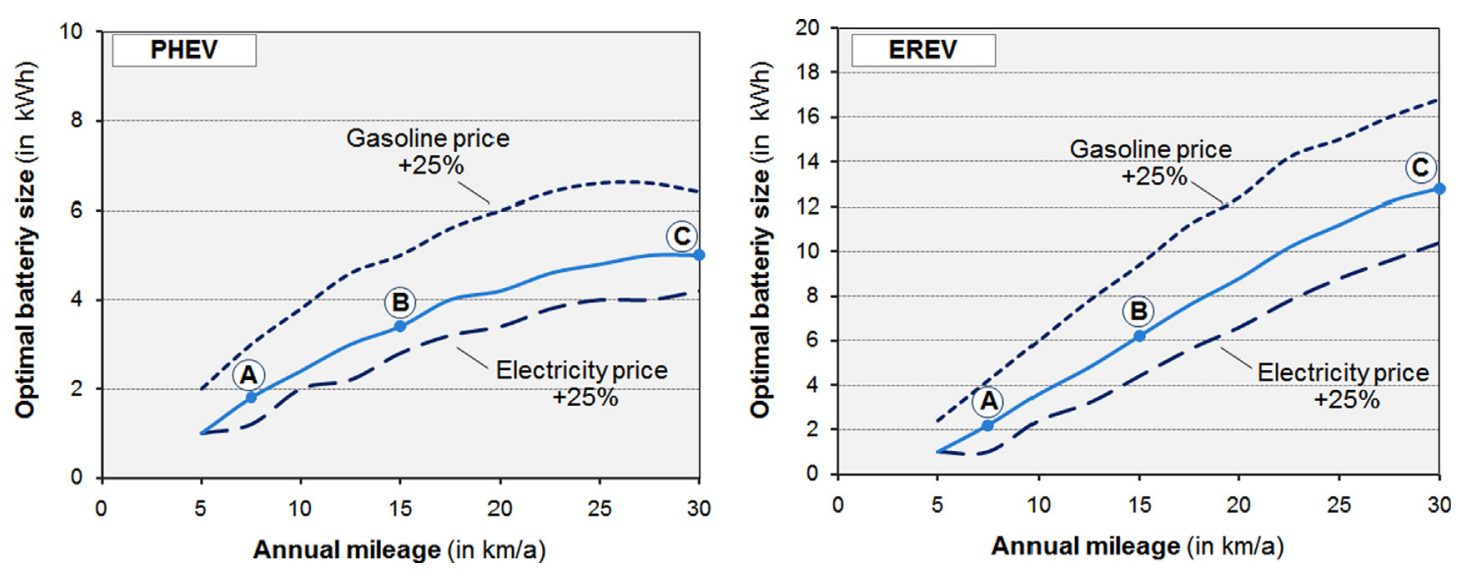

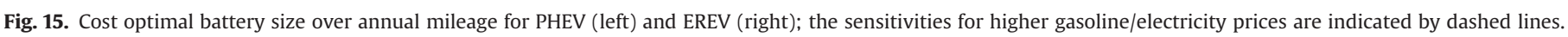

groups for these models. The initial price difference for the Volt EREV pays off only for frequent drivers due to low energy costs per mile. However, the battery is over dimensioned even for a driver with high annual mileage with $30,000 \mathrm{~km} / \mathrm{a}$. The Panamera is positioned in the luxury car segment, where customers expect high quality and performance. However, to make PHEVs and EREVs more attractive for average customers and cost competitive to conventional powertrain technologies in the mass market, the battery should be dimensioned close to the TCO optimum.

It should be underlined that the presented analysis focuses on a cost-optimal battery configuration from a customer perspective. From an OEM's point of view there are additional aspects which influence the battery design decision: Important boundary conditions are set by the $\mathrm{CO}_{2}$ and tax legislation issued by the national governments. The emission and fuel economy standards, that automotive manufacturer are required to meet, will become more and more restrictive over the next decade. As the electric range of a plug in hybrid has a direct impact on the emissions level in certification tests, OEMs might tend to install larger batteries to reduce their corporate average fleet emissions. Furthermore, in some regions the regulation provides super credits, if the $\mathrm{CO}_{2}$ emissions of a car are below a certain limit. According to the latest proposal of the Environmental Committee of EU parliament (2013) new cars with specific emissions of less than $50 \mathrm{~g} \mathrm{CO}_{2} / \mathrm{km}$ will be multiplied by a factor of 2.5 in 2015 ( 2 in 2020) in the calculation of the OEM fleet average. According to the ZEV-II regulation introduced by California and other US states, the credits, which an OEM can earn by selling $\mathrm{EVs}$, is directly linked to the electric driving range of the car. Similarly the Chinese legislation for the period past 2016 (which is still in discussion) will probably provide multiple credits for so called new energy vehicles with an electric range greater than $50 \mathrm{~km}$. Manufacturers will try to meet these targets when dimensioning the battery of a new PHEV model in the development process. Furthermore, the packaging of the car as well as weight requirements set up fixed boundary conditions in the design of the battery storage. So, even if a high battery capacity might be attractive from a TCO and an emission point of view, engineers will often be forced to limit the battery size to a certain level due to other requirements. This is especially relevant for hybrid cars in conversion design. In newly developed vehicle concepts in purpose design (like Tesla Model S or BMW i3) there are more degrees of freedom to integrate the battery in the car (e.g. in the underbody), which allows a more flexible sizing of the battery pack.

From an environmental perspective, grid connected hybrid electric cars have a significant GHG abatement potential depending on the installed battery capacity. As shown in Fig. 16, the direct $\mathrm{CO}_{2}$ emissions (TTW) of an EREV decrease from $120 \mathrm{~g} / \mathrm{km}$ to $25 \mathrm{~g} / \mathrm{km}$ when the battery size is increased from 1 to $20 \mathrm{kWh}$. However, the picture is less

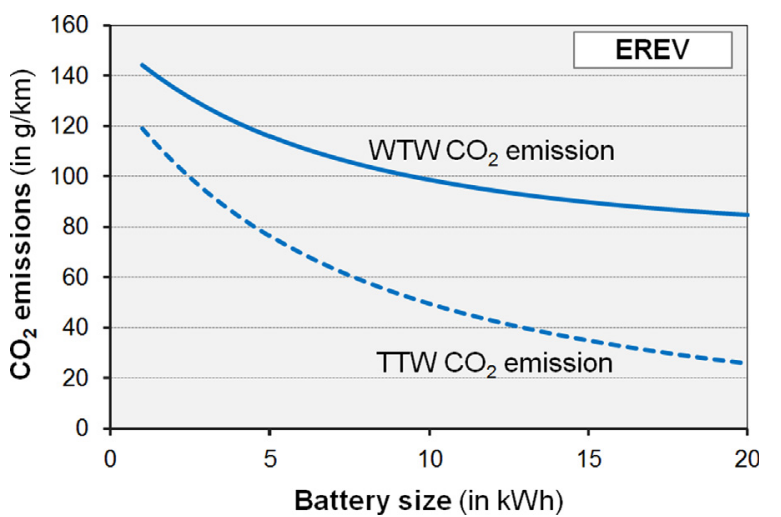

Fig. 16. Average specific $\mathrm{CO}_{2}$ emissions (TTW and WTW) of an EREV as a function of battery size (calculated for user B with 15,000 km/a) for the year 2020 in Germany.

optimistic when indirect emissions (WTW) for the electricity generation are also taken into account. In this case the specific WTW $\mathrm{CO}_{2}$ emissions of the EREV are only in the range of $144-85 \mathrm{~g} / \mathrm{km}$. This is still lower than the majority of current conventional cars which are powered only by an internal combustion engine. Moreover, the analysis in Fig. 16 assumes $\mathrm{CO}_{2}$ emission factor of $75.2 \mathrm{~g} / \mathrm{MJ}$ for electricity charged from the grid as projected for electricity mix in Germany in 2020 by BMU (2012). If in the future, the electric energy required to charge electric vehicle is generated merely by wind or solar power, the WTW emissions will be significantly lower (converging towards the TTW emission line in Fig. 16).

\section{Conclusions and policy implications}

The paper presents a methodology how to find a cost optimal battery setup for plug-in hybrid and range extended electric vehicles for different user types. The analysis shows that the battery size has a significant effect on the total cost of ownership for the customer and, therefore, for the competitive position of the car in the market. For a typical German driver with an annual mileage of $15,000 \mathrm{~km}$, a battery capacity of $4 \mathrm{kWh}$ in case of PHEV and $6 \mathrm{kWh}$ in case of EREV seem to be suitable. However, this value strongly depends on the driving profile of the user (e.g. for an EREV, the optimal size changes to $2 \mathrm{kWh}$ or $13 \mathrm{kWh}$ if the annual mileage is halved or doubled, respectively). Moreover, the optimal battery size is also affected by external factors, especially electricity and fuel prices have a significant impact. Based on these results it is recommended to customize the battery size with respect to the driving behavior of the 
user to make hybrid electric vehicle more cost competitive and attractive for different driver types. Therefore, OEMs should develop a modular design for their battery packs which allows adapting the storage capacity to meet different customer requirements (instead today's "one size fits all" product strategy). The modular design strategy does not imply that the OEMs should offer for each customer an individual battery size. However, a suitable strategy could be to design (for example) three different battery sizes dedicated to drivers with low, average and high mileage, similar to the cars that are offered with different engine sizes. The development of a modular design for battery packs could help OEMs to change the sizes with less effort and few implications on the rest of the vehicle.

The results of this paper imply that higher battery capacities would reduce the overall WTW GHG emissions. If the political target is to reduce the GHG emissions even further by encouraging OEMs to design higher battery sizes for PHEVs and EREVs, the public authorities may influence the results of TCO by different measures. This can happen in basically two ways: On customer side financial incentives could be provided in the form of a direct purchase bonus or tax benefits which are linked to the battery size or the electric driving range of the new car. Furthermore, policy makers may increase the petrol price by increasing the taxes on it. On OEM side, the legal $\mathrm{CO}_{2}$ regulations could contain norms that reward manufacturer with additional credits depending on the electric driving range of their partial zero emission vehicles (as realized in the ZEV legislation in California). Finally, the electricity to operate plug-in hybrid vehicles in electric mode should be provided from renewable energy sources, to reach their full environmental benefit.

It should be noted that this paper assumes a rational customer who has the objective to minimize the total cost of ownership. In reality, the behavior of consumers may not be fully rational. Consumers may prefer higher electric range due to several reasons. This phenomenon may be analyzed in the future and the factors that may distort a rational choice may be identified.

\section{Acknowledgments}

The authors appreciate the efforts of Stephan Schmid for editing and helpful comments on the work.

\section{References}

ADAC, 2010. Autokosten, Munich.

Bandivadekar, A., Bodek, K., Cheah, L., Evans, C., Groode, T., Heywood, J., Kasseris, E. Kromer, M., Weiss, M., 2008. On the Road in 2035: Reducing Transportation's Petroleum Consumption and GHG Emissions. MIT Laboratory for Energy and the Environment, Cambridge, Massachusetts.

Braess, H.-H., 2012. Vieweg Handbuch Kraftfahrzeugtechnik. Vieweg+Teubner Verlag, Wiesbaden (aktualisierte und erweiterte Auflage).

Braun, F., 2012. Kostenentwicklung von Traktions-Elektromotoren und Leistungselektronik. Bachelorarbeit, FH-Köln.

DLR \& Infas, 2010. Mobilität in Deutschland (MiD) 2008. In: Bundesministeriums Für Verkehr Bau Und Stadtentwicklung - BMVBS, Bonn/Berlin.

EC. 2012. Road transport: Reducing CO2 emissions from vehicles. Available at: $\langle$ http://ec.europa.eu/clima/policies/transport/vehicles/index_en.htm〉 (Accessed July 2013)

EEA. 2013. Greenhouse gas emission trends (CSI 010) - Assessment published May 2013. Available at: 〈http://www.eea.europa.eu/data-and-maps/indicators/green house-gas-emission-trends/greenhouse-gas-emission-trends-assessment-5 (Accessed July 2013)
Ernst, C.-S., Hackbarth, A., Madlener, R., Lunz, B., Uwe Sauer, D., Eckstein, L., 2011 Battery sizing for serial plug-in hybrid electric vehicles: a model-based economic analysis for Germany. Energy Policy 39, 5871-5882.

European Commission, 2011. Roadmap to a Single European Transport Area Towards a competitive and resource efficient transport system, White Paper on Transport, Brussels.

European Parliament, 2013. Draft report on the proposal for a regulation of the European Parliament and of the Council amending Regulation (EC) No 443/ 2009 to define the modalities for reaching the 2020 target to reduce $\mathrm{CO}_{2}$ emissions from new passenger cars, European Parliament's Committee on the Environment PHaFS (ed.)

Fraunhofer, I.S.I., 2013. Markthochlaufszenarien für Elektrofahrzeuge. Studie im Auftrag der acatech und der Arbeitsgruppe 7 der Nationalen Plattform Elektromobilität, Karlsruhe.

Hülsebusch, D., Ungethüm, J., Braig, T., Dittus, H., 2009. Multidisciplinary simulation of vehicles. ATZ worldw. 111, 50-55.

Kroll, M., 2011. Kostenentwicklung von Traktionsbatterien. Diplomarbeit, Technische Universität Freiberg.

Malen, D., Reddy, K., 2007. Preliminary Vehicle Mass Estimation Using Empirical Subsystem Influence Coefficients. Auto/Steel Partnership, Southfield, Michigan.

Mock, P., 2010. Entwicklung eines Szenariomodells zur Simulation der zukünftigen Marktanteile und $\mathrm{CO}_{2}$-Emissionen von Kraftfahrzeugen (VECTOR21). DLR Köln.

Mock, P., Hülsebusch, D., Ungethüm, J., Schmid, S., 2009. Electric vehicles - a mode based assessment of future market prospects and environmental impacts. In Proceedings of the 24th International Battery, Hybrid and Fuel Cell Electric Vehicle Symposium \& Exhibition - EVS24, 2009, Stavanger.

Özdemir, E.D., Hartmann, N., 2012. Impact of electric range and fossil fuel price level on the economics of plug-in hybrid vehicles and greenhouse gas abatement costs. Energy Policy 46, 185-192.

Peterson, S.B., Michalek, J.J., 2013. Cost-effectiveness of plug-in hybrid electric vehicle battery capacity and charging infrastructure investment for reducing US gasoline consumption. Energy Policy 52, 429-438.

Peterson, S.B., Whitacre, J., Apt, J., 2011. Net air emissions from electric vehicles: the effect of carbon price and charging strategies. Environ. Sci. Technol. 45 $1792-1797$.

Plötz, P., Kley, F., Gnann, T., 2012. Optimal battery sizes for plug-in-hybrid electric vehicles, In: Proceedings of the International Battery, Hybrid and Fuel Cell Electric Vehicle Symposium - EVS26, Los Angeles.

Propfe, B., Kroll, M., Friedrich, H.E., 2012a. Potential cost-degression of lithium-ion batteries. In: Proceedings of the Kraftwerk Batterie Tagung, 6.-7. März 2012 Münster.

Propfe, B., Redelbach, M., Santini, D.J., Friedrich, H., 2012b. Cost analysis of plug-in hybrid electric vehicles including maintenance \& repair costs and resale values. In: Proceedings of the International Battery, Hybrid and Fuel Cell Electric Vehicle Symposium (EVS26), Los Angeles, USA.

Redelbach, M., Klötzke, M. \& Horst E.F., 2012a. Impact of lightweight design on energy consumption and cost effectiveness of alternative powertrain concepts. In: Proceedings of the European Electric Vehicle Conference (EEVC), Brüssel, Belgium.

Redelbach, M., Propfe, B., \& Friedrich, H.E., 2012b. Competitive cost analysis of alternative powertrain technologies. In: Proceedings of the Internationa Advanced Mobility Forum -IAMF 5, Geneva.

Redelbach, M., Sparka, M., \& Friedrich, H.E., 2013. Modelling customer choice and market development for future automotive powertrain technologies. In: Proceedings of the International Battery, Hybrid and Fuel Cell Electric Vehicle Symposium (EVS27), Barcelona.

Rousseau, A., Redelbach, M., Le Berr, F., Badin, F., Kim, N., Da Costa, A., Santini, D., Friedric H.H., 2012. Comparison of energy consumption and costs of different HEVs and PHEVs in European and American context. In: Proceedings of the European Electric Vehicle Conference - EEVC, Brüssel.

Shiau, C.-S.N., Kaushal, N., Hendrickson, C.T., Peterson, S.B., Whitacre, J.F., Michalek, J.J., 2010. Optimal plug-in hybrid electric vehicle design and allocation for minimum life cycle cost, petroleum consumption, and greenhouse gas emissions. J. Mech. Des. 132, 091013-1-091013-11.

Shiau, C.-S.N., Michalek, J.J., 2011. Global optimization of plug-in hybrid vehicle design and allocation to minimize life cycle greenhouse gas emissions. J. Mech. Des., 133.

Shiau, C.-S.N., Samaras, C., Hauffe, R., Michalek, J.J., 2009. Impact of battery weight and charging patterns on the economic and environmental benefits of plug-in hybrid vehicles. Energy Policy 37, 2653-2663.

Wallentowitz, H., 2011. Strategien zur Elektrifizierung des Antriebsstranges. Vieweg + Teubner Verlag, Wiesbaden.

Wu, X., Cao, B., Li, X., Xu, J., Ren, X., 2011. Component sizing optimization of plug-in hybrid electric vehicles. Appl. Energy 88, 799-804. 